\title{
Intrathoracic Pressure Regulation Improves 24-Hour Survival in a Pediatric Porcine Model of Hemorrhagic Shock
}

\author{
ANJA METZGER, TIMOTHY MATSUURA, SCOTT MCKNITE, BRADLEY S. MARINO, VINAY M. NADKARNI, \\ AND DEMETRIS YANNOPOULOS
}

\begin{abstract}
Department of Emergency Medicine [A.M.], Department of Cardiology [D.Y.], University of Minnesota, Minneapolis, Minnesota 55455; Department of Research [A.M., T.M.], Advanced Circulatory Systems, Inc., St. Paul, Minnesota 55113; Department of Research [S.M.], Minneapolis Medical Research Foundation, Minneapolis, Minnesota 55455; Department of Pediatrics [B.S.M.], Cincinnati Children's Hospital Medical Center, University of Cincinnati College of Medicine, Cincinnati, Ohio 45229; Department of Anesthesia, Critical Care, and Pediatrics [V.M.N.], The Children's Hospital of Philadelphia, University of Pennsylvania School of Medicine, Philadelphia,
\end{abstract}

Pennsylvania 19104

\begin{abstract}
Hemorrhagic shock is a common cause of mortality and morbidity in the pediatric population. Intrathoracic pressure regulation (IPR) lowers intrathoracic pressure, thereby decreasing intracranial pressure and increasing venous return, cardiac output, and cerebral perfusion without the need for immediate fluid resuscitation. We hypothesized that IPR would improve hemodynamics and 24-h survival in a pediatric porcine model of hemorrhagic shock. Twenty piglets were subjected to a $50 \%$ total blood volume hemorrhage over $15 \mathrm{~min}$ and then randomized to treatment with either IPR or no treatment. After $60 \mathrm{~min}$, survivors were autotransfused, weaned from the ventilator, and assessed and autopsied at $24 \mathrm{~h}$. Mean arterial pressures (MAPs), cardiac index (CI), and arterial blood gases were recorded. MAP $(\mathrm{mm} \mathrm{Hg})$ was significantly higher in the IPR group $(60.8 \pm 3.7)$ versus controls $(41.2 \pm 4.6, p<0.01)$. Mean CI $\left(\mathrm{L} / \mathrm{min} / \mathrm{m}^{2}\right)$ was significantly higher with IPR (3.9 \pm 0.24$)$ versus controls $(2.5 \pm 0.39, p<0.01)$. IPR survival rates were significantly improved with IPR [9/9 (IPR) versus 5/11 (controls); $p<0.02]$. In this piglet model of hemorrhagic shock, IPR treatment safely and significantly improved MAP, CI, and 24-h survival rates. (Pediatr Res 70: 267-271, 2011)
\end{abstract}

$\mathrm{H}$ emorrhagic shock remains a significant cause of mortality and morbidity in the pediatric population. Fluid resuscitation is the mainstay of therapy, although it is often insufficient. Venous access, hemodilution, decreased oxygencarrying capacity of standard resuscitation fluids, and clotting factor dilution, all contribute to the challenges of fluid resuscitation in the absence of whole blood. A new device, based on the principles of intrathoracic pressure regulation (IPR), has recently been shown to increase venous return and cardiac preload, cardiac stroke volume (SV), cardiac output (CO), and thus mean arterial pressure (MAP), in apneic, intubated adult swine during hypovolemic hypotension (1). An increase in survival and cerebral perfusion pressures with a concomitant decrease in intracranial pressure (ICP) has also been observed $(2,3)$. This technology has more recently been shown to be similarly effective in patients (4). The IPR device is portable, lightweight, and can be inserted between the endotracheal tube

Received November 29, 2010; accepted March 29, 2011.

Correspondence: Anja Metzger, Ph.D., 1905 Cty Rd C West, St. Paul, MN 55113; e-mail: koh10005@umn.edu

Supported by the National Institutes of Health (Grant 5R43HL083541-02). and a ventilation source (Fig. 1). It allows for the delivery of an unrestricted positive pressure breath from an external source (ventilator or resuscitator bag) and then generates a continuous low-level subatmospheric pressure of up to -12 $\mathrm{cm} \mathrm{H}_{2} \mathrm{O}$ by actively extracting respiratory gases during the expiratory phase between positive pressure ventilations (PPVs; Fig. 2).

To date, preclinical studies with IPR have been limited to studies in adult $(>30 \mathrm{~kg})$ animals $(1-3,5,6)$. However, chest wall, heart, tracheal and lung anatomy, and physiology is different in pediatric patients compared with adults. Thus, the primary purpose of this investigation was to evaluate the potential hemodynamic and survival benefits of IPR in a relevant pediatric model of hypovolemic hypotension. In addition, a secondary purpose was to determine whether this new therapy could be safely used without causing increased pulmonary edema or atelectasis because treatment with IPR can be thought of as negative end-expiratory pressure (NEEP), the opposite of positive-end expiratory pressure (PEEP). We hypothesized that IPR would result in improved cardiac index (CI), systolic blood pressure (SBP), and survival without compromising lung function.

\section{METHODS}

The study was approved by the Institutional Animal Care and Use Committee of the Minneapolis Medical Research Foundation at Hennepin County Medical Center, Minneapolis, MN. The animals received treatment and care in compliance with the 1996 Guide for the Care and Use of Laboratory Animals by the National Research Council, in accordance with the United States Department of Agriculture Animal Welfare Act, Public Health Service Policy, and the American Association for Accreditation of Laboratory Animal Care. Anesthesia was used in all surgical interventions to avoid all unnecessary suffering.

Preparatory phase. This study was performed on $12 \mathrm{~kg}$ female domestic crossbreed piglets $(\sim 7 \mathrm{wk}$ old). Initial sedation was done with $500 \mathrm{mg}$ of

\footnotetext{
Abbreviations: BSA, body surface area; bpm, breaths per minute; CI, cardiac index; CO, cardiac output; $\mathbf{E T C O}$, end-tidal $\mathrm{CO}_{2}$; ETP, endotracheal pressure; ICP, intracranial pressure; IPR, intrathoracic pressure regulation; ITD, impedance threshold device; ITP, intrathoracic pressure; LPM, liters per minute; MAP, mean arterial pressure; NIP, negative inspiratory pressure (peak); PIP, peak inspiratory pressure; PPV, positive pressure ventilation; RAP, right atrial pressure; RR, respiratory rate; $\mathbf{S V}$, stroke volume
} 


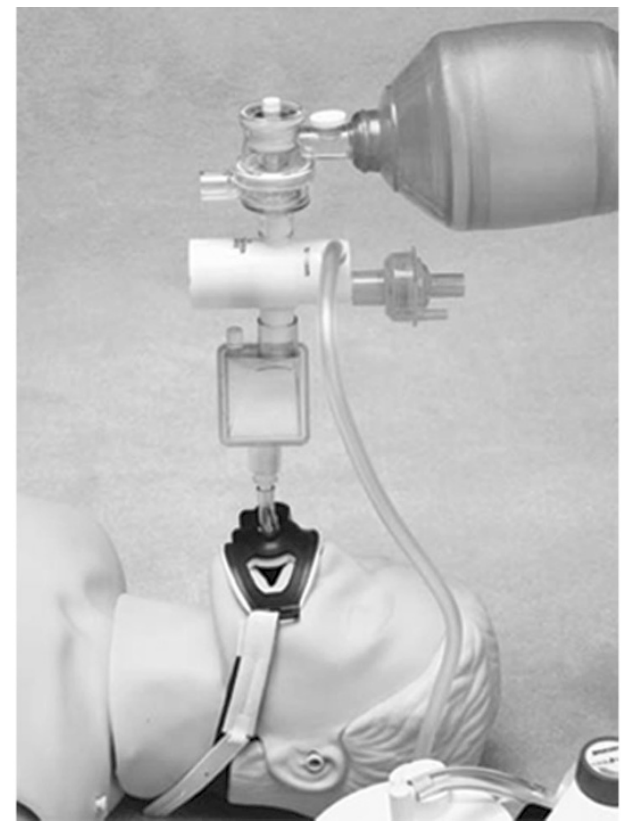

Figure 1. Photo of the IPR device connected to a ventilation circuit with filter and airway pressures during its use. In clinical use, a filter is recommended to minimize any possible accumulation of secretions in the device. A filter was not used in the piglet studies.

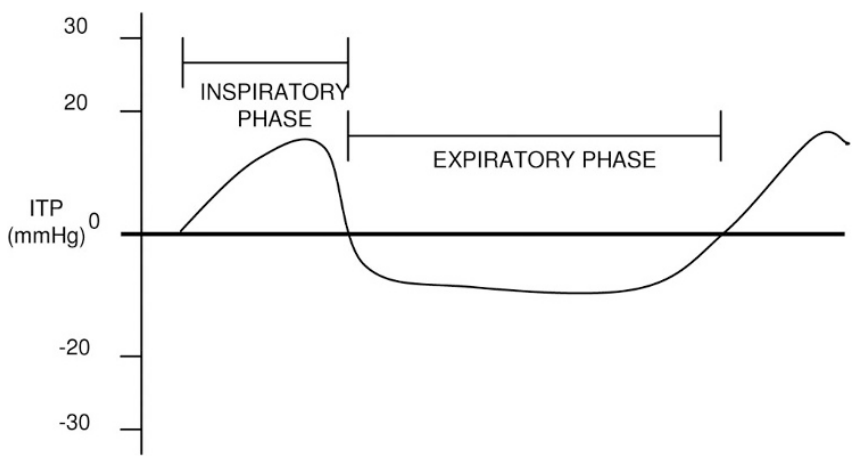

Figure 2. Pressure curve illustrating the ITP wave form obtained during IPR use.

intramuscular ketamine (Bioniche Pharma USA LLC, Lake Forest, IL). After intubation with a $5.5-\mathrm{mm}$ cuffed endotracheal tube, isofluorane (Baxter Healthcare Corporation, Deerfield, IL) was administered at $1.5-2.0 \%$. On completion of the surgical preparation, isofluorane was decreased to $1.0 \%$ and was maintained at $1.0 \%$ throughout the interventions. Unilateral femoral artery and bilateral jugular vein cannulations were performed in the supine position. Central aortic pressure at the level of the diaphragm and right atrial pressure (RAP) were recorded continuously with 5-Fr micromanometertipped catheters (Mikro-Tip Transducer, Millar Instruments, Houston, TX). A pulmonary artery catheter was placed under pressure tracing guidance. $\mathrm{CO}$ was measured by the thermodilution method (Edwards Lifesciences, Irvine, CA). The right common carotid artery was surgically exposed, and an ultrasonic flow probe (Transonic Systems Inc., Ithaca, NY) was placed around the artery to quantify blood flow. All animals were treated with an i.v. heparin bolus (100 units $/ \mathrm{kg}$ ) once catheters were in place to prevent the formation of clots. During the preparatory phase, animals were ventilated with 0.35 fraction of inspired oxygen $\left(\mathrm{FiO}_{2}\right)$ via a volume-control ventilator (Narkomed 2A, North American Drager, Telford, PA), with a tidal volume of $10 \mathrm{~mL} / \mathrm{kg}$, PEEP of $3 \mathrm{~cm} \mathrm{H}_{2} \mathrm{O}$, and the rate was adjusted to continually maintain end-tidal $\mathrm{CO}_{2}\left(\mathrm{ETCO}_{2}\right)$ between 38 and $42 \mathrm{~mm} \mathrm{Hg}$ and transcutaneous $\mathrm{O}_{2}$ saturation $>95 \%\left(\mathrm{CO}_{2} \mathrm{SMO}\right.$ Plus, Novametrix Medical Systems, Wallingford, CT). Endotracheal pressure (ETP) was measured continuously with a micromanometer-tipped catheter positioned in the endotracheal tube $2 \mathrm{~cm}$ above the carina. All data were recorded by a digital recording system (Biopac Systems Inc., Goleta, CA).
Hemodynamic variables measured included central aortic (systolic, diastolic, and mean) and RAPs, carotid artery blood flow, heart rate, and CO. CI was calculated by dividing $\mathrm{CO}$ by body surface area (BSA). BSA was calculated using the formula of Kelley et al. (7) for female swine: BSA $\left(\mathrm{m}^{2}\right)=0.0734$ weight $(\mathrm{kg})^{0.656}$. Respiratory variables measured included respiratory rate $(\mathrm{RR}), \mathrm{ETCO}_{2}$, inspiratory tidal volume, expiratory tidal volume, peak inspiratory pressure (PIP), and peak negative inspiratory pressure (NIP). Arterial and venous blood gas parameters measured included $\mathrm{pH}$, $\mathrm{PCO}_{2}, \mathrm{PO}_{2}$, lactate, hematocrit, bicarbonate, arterial and venous oxygen saturation, and base excess. All parameters were analyzed at euvolemic baseline ( $3 \mathrm{~min}$ before start of hemorrhage); hypovolemic baseline (15 min after the conclusion of a controlled hemorrhage); and every 15 min during the 60-min treatment intervention. Hemodynamic data were obtained by measuring four consecutive cardiac cycles just before the delivery of a PPV. These measurements were repeated three times within each minute studied for a total of 12 measurements. The mean of these measurements is the value reported at each designated time point. Common carotid artery blood flow was reported as peak and mean flow in milliliters per minute. Arterial and mixed venous blood gases were analyzed in real time with a blood gas machine (Instrumentation Laboratories, Bedford, MA).

Experimental protocol. Euvolemic baseline data were collected just before the start of the hemorrhage. Animals were then subjected to a controlled bleed of $50 \%$ of calculated blood volume using the equation: total volume $=$ weight $(\mathrm{kg}) \times 85 \mathrm{~mL} / \mathrm{kg}$. After the hemorrhage, all animals were treated with a paralytic $(0.20 \mathrm{mg} / \mathrm{kg}$ i.v. succinylcholine bolus then $93.3 \mu \mathrm{g} / \mathrm{kg} / \mathrm{min}$ continuous infusion) to prevent spontaneous gasping which is induced by IPR use. A 15-min no intervention recovery period was then followed by either IPR or no IPR (control or PPV) therapy. In pilot studies, it was recognized that no animals with a base excess greater than $-9 \mathrm{mM}$ measured $15 \mathrm{~min}$ after the bleed could survive the hemorrhage protocol. As such, in this protocol, only animals with a base excess between 0 and $-9 \mathrm{mM}$ measured $15 \mathrm{~min}$ after the bleed were evaluated in this study. The IPR device (CirQLATOR ${ }^{\circledR}$; Advanced Circulatory Systems, Inc., Roseville, MN) is designed to allow for PPV from a separate source such as a ventilator or anesthesia machine. After each PPV, the IPR device generates a constant negative intrathoracic pressure (ITP) of approximately $-12 \mathrm{~cm} \mathrm{H}_{2} \mathrm{O}$ until the next PPV. Tidal volume and RR during the control intervention in this study were $10 \mathrm{~mL} / \mathrm{kg}$ and $8-18$ breaths per minute (bpm) (adjusted during treatment in the control pigs to maintain an $\mathrm{ETCO}_{2}$ between 40 and $45 \mathrm{~mm} \mathrm{Hg}$ ). Tidal volume and RR when the IPR device was used were $10 \mathrm{~mL} / \mathrm{kg}+50 \mathrm{~mL}$ and $10-12 \mathrm{bpm}$ (adjusted during treatment to maintain and ETCO2 between 40 and $45 \mathrm{~mm} \mathrm{Hg}$ ). A lower RR is preferential in the IPR group to maximize the duration of time at negative ITP. All animals were ventilated with an $\mathrm{FiO}_{2}$ of 0.35 . After 60 -min of treatment (IPR versus control), shed blood was reinfused and catheter sites repaired. Animals were then weaned from the ventilator and allowed to recover for $24 \mathrm{~h}$ at which time they were evaluated and then euthanized. Autopsies were performed on all animals to evaluate for atelectasis and pulmonary edema. Lung tissue samples for histology and wet to dry weight ratios were taken to assess lung damage in animals that survived for $24 \mathrm{~h}$.

Statistical analysis. Values are expressed as mean \pm SEM. Hemodynamic, respiratory, and blood gas variables were compared between treatments using a $t$ test. Sixty-minute and 24-h survival rates were analyzed using a Fischer's exact test and Kaplan-Meier method with log-rank comparison of cumulative survival. A $p$-value of $<0.05$ was considered statistically significant.

\section{RESULTS}

Eleven piglets $\sim 7 \mathrm{wk}$ old, weighing $12.1 \pm 0.3 \mathrm{~kg}$, were randomized to the control group, and nine piglets, weighing $12.5 \pm 0.2 \mathrm{~kg}$, were randomized to treatment with IPR. IPR significantly reduced ETP and increased systolic blood pressure, mean arterial blood pressure, and $\mathrm{CI}$ as shown in Figure 3. Mean carotid flow, averaged over the 60-min intervention period, was significantly higher in the IPR group $(70 \mathrm{~mL} / \mathrm{min} \pm 6.0$ versus 48 $\mathrm{mL} / \mathrm{min} \pm 9.1 ; p=0.05)$. RAP and ETP during expiratory phase were significantly lower with IPR during all time points (mean of $-5.3 \pm 0.3$ and $-8.2 \pm 0.2$ versus $-1.1 \pm 0.3 \mathrm{~mm} \mathrm{Hg}$ and $1.4 \pm 0.2 \mathrm{~mm} \mathrm{Hg}$, respectively, $p<0.001$ ).

Respiratory variables are shown in Table 1 . Tidal volume was intentionally increased during IPR use and RR was varied between 10 and $12 \mathrm{bpm}$ to maintain $\mathrm{ETCO}_{2}$ between 40 and $45 \mathrm{~mm}$ $\mathrm{Hg}$. It is appreciated that the varying RR between interventions 

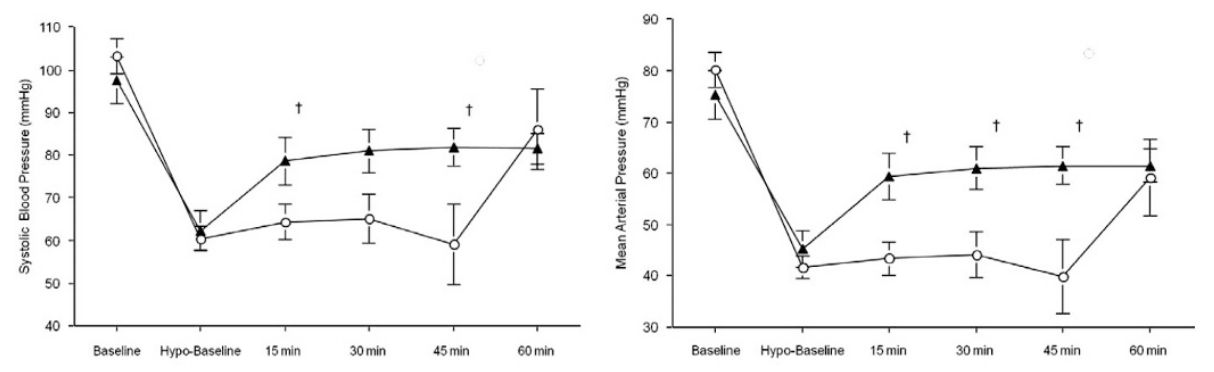

Figure 3. Comparison of systolic blood pressure, mean arterial pressure, cardiac output, and intrathoracic pressure between IPR $(\boldsymbol{\Lambda})$ and control $(\bigcirc)$ groups. $n=9$ for all time points in IPR group. In the control group, $n=11$ at baseline, hypovolemic baseline (15 min after bleed is complete), and $15 \min ; n=10$ at $30 \mathrm{~min} ; n=$ 9 at $45 \mathrm{~min}$; and $n=5$ at $60 \mathrm{~min} . \dagger p<0.05$.
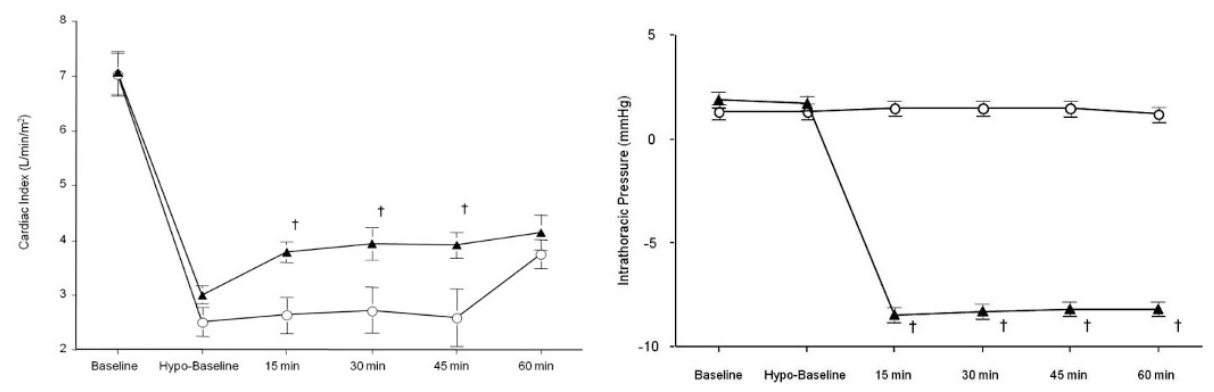

Table 1. Respiratory variables

\begin{tabular}{|c|c|c|c|c|c|c|c|c|}
\hline & $\begin{array}{l}\text { Treatment } \\
\text { group }\end{array}$ & $\begin{array}{c}\text { Euvolemic } \\
\text { baseline }\end{array}$ & $\begin{array}{c}\text { Hypovolemic } \\
\text { baseline }\end{array}$ & $\begin{array}{c}\text { Intervention } \\
15 \mathrm{~min}\end{array}$ & $\begin{array}{l}\text { Intervention } \\
30 \text { min }\end{array}$ & $\begin{array}{c}\text { Intervention } \\
45 \mathrm{~min}\end{array}$ & $\begin{array}{l}\text { Intervention } \\
60 \mathrm{~min}\end{array}$ & $\begin{array}{l}\text { Intervention } \\
\text { total }\end{array}$ \\
\hline \multirow[t]{2}{*}{$\mathrm{ETCO}_{2}(\mathrm{~mm} \mathrm{Hg})$} & Control & $45 \pm 1$ & $45 \pm 1$ & $48 \pm 2$ & $49 \pm 2$ & $47 \pm 3$ & $54 \pm 2$ & $46 \pm 3$ \\
\hline & IPR & $45 \pm 1$ & $46 \pm 0$ & $46 \pm 2$ & $46 \pm 2$ & $47 \pm 3$ & $47 \pm 3^{*}$ & $47 \pm 2$ \\
\hline \multirow{2}{*}{$\mathrm{RR}(\mathrm{bpm})$} & Control & $20 \pm 0$ & $15 \pm 1$ & $13 \pm 1$ & $13 \pm 1$ & $13 \pm 1$ & $16 \pm 0$ & $12 \pm 1$ \\
\hline & IPR & $21 \pm 1$ & $16 \pm 1$ & $10 \pm 0^{*}$ & $10 \pm 0^{*}$ & $10 \pm 0$ & $11 \pm 1^{*}$ & $10 \pm 0 *$ \\
\hline \multirow{2}{*}{ Ins TV (mL) } & Control & $126 \pm 3$ & $125 \pm 3$ & $124 \pm 3$ & $123 \pm 3$ & $121 \pm 4$ & $123 \pm 4$ & $124 \pm 3$ \\
\hline & IPR & $130 \pm 4$ & $126 \pm 2$ & $165 \pm 6 \dagger$ & $170 \pm 6 \dagger$ & $174 \pm 5 \dagger$ & $171 \pm 5 \dagger$ & $170 \pm 5 \dagger$ \\
\hline \multirow[t]{2}{*}{ Exp TV (mL) } & Control & $122 \pm 4$ & $125 \pm 4$ & $124 \pm 6$ & $122 \pm 6$ & $116 \pm 6$ & $120 \pm 6$ & $124 \pm 6$ \\
\hline & IPR & $125 \pm 4$ & $131 \pm 3$ & $193 \pm 8 \dagger$ & $189 \pm 7 \dagger$ & $191 \pm 9 \dagger$ & $187 \pm 8 \dagger$ & $190 \pm 8 \dagger$ \\
\hline \multirow[t]{2}{*}{ PIP $\left(\mathrm{cm} \mathrm{H}_{2} \mathrm{O}\right)$} & Control & $16 \pm 1$ & $17 \pm 1$ & $17 \pm 1$ & $17 \pm 1$ & $17 \pm 1$ & $17 \pm 1$ & $17 \pm 1$ \\
\hline & IPR & $15 \pm 0$ & $16 \pm 0$ & $12 \pm 1^{*}$ & $13 \pm 1 \dagger$ & $15 \pm 1 *$ & $15 \pm 1$ & $14 \pm 1 *$ \\
\hline \multirow{2}{*}{$\mathrm{NIP}\left(\mathrm{cm} \mathrm{H} \mathrm{H}_{2} 0\right)$} & Control & $0 \pm 0$ & $0 \pm 0$ & $0 \pm 0$ & $0 \pm 0$ & $0 \pm 0$ & $0 \pm 0$ & $0 \pm 0$ \\
\hline & IPR & $0 \pm 0$ & $0 \pm 0$ & $-10 \pm 0 \dagger$ & $-10 \pm 0 \dagger$ & $-9 \pm 0 \dagger$ & $-9 \pm 0 \dagger$ & $-10 \pm 0 \dagger$ \\
\hline
\end{tabular}

$\mathrm{RR}$, respiratory rate; Ins and Exp TV, inspiratory and expiratory tidal volume (mL).

$* p<0.05$.

$\dagger p<0.001$.

could confound the data. However, no significant differences in minute ventilation were documented between groups $[1.6 \pm 0.1$ liters per minute (LPM) (control) versus $1.7 \pm 0.1 \mathrm{LPM}$ (IPR) at $15 \mathrm{~min} ; 1.6 \pm 0.1 \mathrm{LPM}$ (control) versus $1.8 \pm 0.1 \mathrm{LPM}$ (IPR) at $30 \mathrm{~min} ; 1.6 \pm 0.2 \mathrm{LPM}$ (control) versus $1.8 \pm 0.1 \mathrm{LPM}$ (IPR) at $45 \mathrm{~min} ; p=\mathrm{NS}$. PIP was reduced during IPR use at 15, 30, and $45 \mathrm{~min}$ even though the delivered tidal volume was increased because it requires a larger tidal volume to change the airway pressure from $-12 \mathrm{~cm} \mathrm{H}_{2} \mathrm{O}$ to $15 \mathrm{~cm} \mathrm{H}_{2} \mathrm{O}$ (IPR therapy) compared with the tidal volume required to move from $3 \mathrm{~cm} \mathrm{H}_{2} \mathrm{O}$ to $15 \mathrm{~cm} \mathrm{H}_{2} \mathrm{O}$ (PPV). The decrease in PIP seen in these studies is a direct result of this. As expected, the NIP for the IPR group was significantly lower during all intervention time points.

Arterial and venous blood gas variables and metabolic markers are shown in Table 2. Arterial and venous $\mathrm{pH}$ values were significantly higher during IPR use $(7.26 \pm 0.01$ and $7.17 \pm 0.01$ versus $7.15 \pm 0.02$ and $7.01 \pm 0.03$, respectively, $p<0.001)$. Importantly, IPR was also able to maintain a lower base deficit and lactate level during its use presumably as a result of the improved circulation with the device, whereas these important metabolic measurements continued to decline in the control group.

Sixty-minute survival between groups was significant based on the Fischer's exact test $(p=0.014)$. A total of 9 of 9 animals treated with IPR versus 5 of 11 control animals survived to blood infusion. For those animals not surviving the 60-min control intervention, the times of death were all less than $60 \mathrm{~min}(21,33$, 47, 47, 53, and $54 \mathrm{~min}$ ). All animals that survived to blood infusion survived to $24 \mathrm{~h}$. Absolute differences in survival time between groups were also significant, $p=0.016$ by Log-Rank (Mantel-Cox) test. All animals that survived to $24 \mathrm{~h}$ were able to walk, eat, urinate, and respond with normal withdrawal characteristics. None of the surviving animals exhibited any signs of respiratory distress (no pulmonary edema).

No significant differences in any markers indicative of lung damage were found. Wet to dry lung tissue ratios were evaluated in the surviving five control animals and the surviving nine animals treated with IPR. No significant differences were found $[5.65 \pm 0.18$ (control) versus $6.03 \pm 0.30$ (IPR); $p=0.31]$. Tissue pathology did not show significant differences between 
Table 2. Arterial and venous blood gas data

\begin{tabular}{|c|c|c|c|c|c|c|c|c|}
\hline & $\begin{array}{l}\text { Treatment } \\
\text { group }\end{array}$ & $\begin{array}{l}\text { Normovolemic } \\
\text { baseline }\end{array}$ & $\begin{array}{c}\text { Hypovolemic } \\
\text { baseline }\end{array}$ & $\begin{array}{l}\text { Intervention } \\
15 \mathrm{~min}\end{array}$ & $\begin{array}{l}\text { Intervention } \\
30 \mathrm{~min}\end{array}$ & $\begin{array}{l}\text { Intervention } \\
45 \mathrm{~min}\end{array}$ & $\begin{array}{l}\text { Intervention } \\
60 \mathrm{~min}\end{array}$ & $\begin{array}{l}\text { Intervention } \\
\text { total }\end{array}$ \\
\hline \multicolumn{9}{|l|}{ Arterial } \\
\hline \multirow{2}{*}{$\mathrm{pH}$} & Control & $7.36 \pm 0.01$ & $7.25 \pm 0.01$ & $7.19 \pm 0.01$ & $7.15 \pm 0.02$ & $7.11 \pm 0.03$ & $7.18 \pm 0.01$ & $7.15 \pm 0.02$ \\
\hline & IPR & $7.36 \pm 0.01$ & $7.23 \pm 0.03$ & $7.25 \pm 0.01 *$ & $7.27 \pm 0.01 \dagger$ & $7.26 \pm 0.01 \dagger$ & $7.26 \pm 0.01 *$ & $7.23 \pm 0.03 \dagger$ \\
\hline \multirow{2}{*}{$\mathrm{PaCO}_{2}(\mathrm{~mm} \mathrm{Hg})$} & Control & $50 \pm 2$ & $48 \pm 1$ & $52 \pm 1$ & $51 \pm 2$ & $50 \pm 3$ & $56 \pm 2$ & $50 \pm 2$ \\
\hline & IPR & $49 \pm 1$ & $49 \pm 1$ & $52 \pm 2$ & $51 \pm 1$ & $52 \pm 1$ & $51 \pm 2$ & $52 \pm 1$ \\
\hline \multirow[t]{2}{*}{$\mathrm{PaO}_{2}(\mathrm{~mm} \mathrm{Hg})$} & Control & $172 \pm 12$ & $149 \pm 8$ & $130 \pm 7$ & $140 \pm 5$ & $137 \pm 9$ & $139 \pm 7$ & $134 \pm 6$ \\
\hline & IPR & $156 \pm 6$ & $160 \pm 6$ & $141 \pm 7$ & $144 \pm 5$ & $145 \pm 5$ & $142 \pm 4$ & $143 \pm 5$ \\
\hline \multirow[t]{2}{*}{ Lactate $(\mathrm{mmol} / \mathrm{L})$} & Control & $1.1 \pm 0.1$ & $4.6 \pm 0.5$ & $5.8 \pm 0.7$ & $6.7 \pm 1.0$ & $7.6 \pm 1.6$ & $4.7 \pm 0.9$ & $6.9 \pm 0.9$ \\
\hline & IPR & $1.3 \pm 0.1$ & $4.1 \pm 0.5$ & $3.7 \pm 0.5^{*}$ & $3.6 \pm 0.5^{*}$ & $3.4 \pm 0.5^{*}$ & $3.4 \pm 0.6$ & $3.5 \pm 0.5^{*}$ \\
\hline \multirow[t]{2}{*}{ Hct $(\%)$} & Control & $24 \pm 1$ & $20 \pm 1$ & $20 \pm 0$ & $20 \pm 1$ & $19 \pm 1$ & $21 \pm 1$ & $20 \pm 1$ \\
\hline & IPR & $24 \pm 1$ & $20 \pm 1$ & $20 \pm 1$ & $19 \pm 1$ & $19 \pm 1$ & $19 \pm 1$ & $20 \pm 1$ \\
\hline \multirow{2}{*}{$\mathrm{HCO}_{3}(\mathrm{mmol} / \mathrm{L})$} & Control & $28.2 \pm 0.7$ & $21.1 \pm 0.6$ & $19.7 \pm 0.8$ & $18.0 \pm 1.2$ & $16.3 \pm 1.8$ & $21.0 \pm 0.2$ & $17.7 \pm 1.0$ \\
\hline & IPR & $27.0 \pm 0.6$ & $22.3 \pm 0.8$ & $23.0 \pm 0.7 *$ & $23.1 \pm 0.7^{*}$ & $24.0 \pm 0.7 *$ & $23.8 \pm 0.8^{*}$ & $23.5 \pm 0.7^{*}$ \\
\hline \multirow[t]{2}{*}{ BE ecf $(\mathrm{mmol} / \mathrm{L})$} & Control & $2.6 \pm 0.7$ & $-6.1 \pm 0.8$ & $-8.6 \pm 1.0$ & $-10.9 \pm 1.6$ & $-12.3 \pm 2.2$ & $-7.3 \pm 0.2$ & $-10.9 \pm 1.3$ \\
\hline & IPR & $1.5 \pm 0.8$ & $-4.7 \pm 0.9$ & $-4.2 \pm 0.8^{*}$ & $-3.8 \pm 0.8 \dagger$ & $-3.0 \pm 0.9 \dagger$ & $-3.2 \pm 0.9^{*}$ & $-3.6 \pm 0.9 \dagger$ \\
\hline \multirow[t]{2}{*}{$\mathrm{SaO}_{2}(\%)$} & Control & $99 \pm 0.1$ & $99 \pm 0.2$ & $98 \pm 0.5$ & $98 \pm 0.3$ & $97 \pm 0.9$ & $99 \pm 0.2$ & $98 \pm 0.5$ \\
\hline & IPR & $99 \pm 0.2$ & $99 \pm 0.1$ & $99 \pm 0.2$ & $99 \pm 0.1$ & $99 \pm 0.2$ & $99 \pm 0.1$ & $99 \pm 0.1$ \\
\hline \multicolumn{9}{|l|}{ Venous } \\
\hline \multirow[t]{2}{*}{$\mathrm{pH}$} & Control & $7.31 \pm 0.01$ & $7.13 \pm 0.02$ & $7.06 \pm 0.02$ & $7.02 \pm 0.04$ & $6.98 \pm 0.05$ & $7.09 \pm 0.01$ & $7.01 \pm 0.03$ \\
\hline & IPR & $7.30 \pm 0.02$ & $7.14 \pm 0.02$ & $7.16 \pm 0.01 *$ & $7.18 \pm 0.02 *$ & $7.17 \pm 0.01 *$ & $7.17 \pm 0.01 *$ & $7.17 \pm 0.01 \dagger$ \\
\hline \multirow[t]{2}{*}{$\mathrm{PaCO}_{2}(\mathrm{~mm} \mathrm{Hg})$} & Control & $60 \pm 2$ & $74 \pm 2$ & $78 \pm 2$ & $83 \pm 4$ & $86 \pm 5$ & $79 \pm 2$ & $83 \pm 3$ \\
\hline & IPR & $56 \pm 1$ & $66 \pm 6^{*}$ & $65 \pm 6^{*}$ & $63 \pm 6^{*}$ & $67 \pm 6^{*}$ & $70 \pm 7$ & $66 \pm 6^{*}$ \\
\hline \multirow[t]{2}{*}{$\mathrm{PaO}_{2}(\mathrm{~mm} \mathrm{Hg})$} & Control & $49 \pm 1$ & $26 \pm 1$ & $26 \pm 3$ & $28 \pm 2$ & $25 \pm 3$ & $31 \pm 2$ & $25 \pm 3$ \\
\hline & IPR & $47 \pm 1$ & $25 \pm 1$ & $30 \pm 1$ & $32 \pm 2$ & $28 \pm 1$ & $28 \pm 1$ & $30 \pm 1$ \\
\hline \multirow[t]{2}{*}{ Lactate $(\mathrm{mmol} / \mathrm{L})$} & Control & $1.1 \pm 0.1$ & $4.5 \pm 0.5$ & $6.0 \pm 0.8$ & $6.9 \pm 1.1$ & $7.7 \pm 1.7$ & $4.8 \pm 0.9$ & $7.2 \pm 1.0$ \\
\hline & IPR & $1.3 \pm 0.1$ & $3.9 \pm 0.5$ & $3.7 \pm 0.5^{*}$ & $3.5 \pm 0.4^{*}$ & $3.4 \pm 0.5^{*}$ & $2.9 \pm 0.3^{*}$ & $3.5 \pm 0.5^{*}$ \\
\hline \multirow{2}{*}{ Hct $(\%)$} & Control & $25 \pm 1$ & $21 \pm 1$ & $22 \pm 1$ & $22 \pm 1$ & $20 \pm 1$ & $22 \pm 1$ & $21 \pm 1$ \\
\hline & IPR & $25 \pm 1$ & $21 \pm 1$ & $21 \pm 1$ & $21 \pm 1$ & $21 \pm 1$ & $22 \pm 1$ & $21 \pm 1$ \\
\hline \multirow[t]{2}{*}{$\mathrm{HCO}_{3}(\mathrm{mmol} / \mathrm{L})$} & Control & $29.1 \pm 0.8$ & $24.2 \pm 0.7$ & $22.2 \pm 0.6$ & $21.1 \pm 1.1$ & $21.6 \pm 1.6$ & $23.7 \pm 0.2$ & $21.2 \pm 0.8$ \\
\hline & IPR & $28.4 \pm 0.6$ & $24.9 \pm 0.9$ & $25.5 \pm 0.7 *$ & $26.0 \pm 1.0^{*}$ & $27.0 \pm 0.9^{*}$ & $27.8 \pm 0.9 *$ & $26.4 \pm 0.9^{*}$ \\
\hline \multirow[t]{2}{*}{ BE ecf $(\mathrm{mmol} / \mathrm{L})$} & Control & $3.5 \pm 0.6$ & $-5.0 \pm 0.8$ & $-8.0 \pm 1.0$ & $-9.9 \pm 1.6$ & $-9.3 \pm 2.4$ & $-6.2 \pm 0.1$ & $-9.8 \pm 1.2$ \\
\hline & IPR & $1.9 \pm 0.7$ & $-4.2 \pm 1.1$ & $-3.2 \pm 0.9 *$ & $-2.3 \pm 1.0 \dagger$ & $-1.6 \pm 1.0^{*}$ & $-0.8 \pm 1.1^{*}$ & $-2.1 \pm 1.0 \dagger$ \\
\hline \multirow[t]{2}{*}{$\mathrm{SvO}_{2}(\%)$} & Control & $79 \pm 2$ & $29 \pm 3$ & $29 \pm 5$ & $28 \pm 5$ & $30 \pm 6$ & $36 \pm 3$ & $25 \pm 4$ \\
\hline & IPR & $77 \pm 2$ & $28 \pm 3$ & $39 \pm 3$ & $43 \pm 5^{*}$ & $36 \pm 2$ & $35 \pm 3$ & $38 \pm 3^{*}$ \\
\hline
\end{tabular}

$\mathrm{PaCO}_{2}$, partial pressure of $\mathrm{CO}_{2} ; \mathrm{PaO}_{2}$, partial pressure of $\mathrm{O}_{2} ; \mathrm{Hct}$, hematocrit; $\mathrm{BE}$ ecf, base excess; $\mathrm{SaO}_{2}$, arterial oxygen saturation; SvO , venous oxygen saturation.

$* p<0.05$

$\dagger p<0.001$.

treatments. There was no evidence of inflammation in either group. Qualitative evidence of interstitial edema and intraalveolar hemorrhage was identified in both treatment groups.

\section{DISCUSSION}

The results of this first assessment of IPR in a pediatric porcine model of severe hemorrhagic hypotension and shock are consistent with prior studies and demonstrate that use of this novel therapy safely improved key physiological parameters and $24 \mathrm{~h}$ survival. These data support the hypothesis that treatment with IPR therapy may be important to prevent the lethal consequence of severe hypotension in critically ill and injured infants and children.

In this study, IPR therapy was well tolerated with no adverse device effects, as assessed by blood gas values including $\mathrm{PO}_{2}$, $\mathrm{pH}$, and lactate and by lung pathology and lung wet to dry ratios $24 \mathrm{~h}$ after treatment. In these piglets, the IPR device decreased ETP. The lowering of ETP, analogous to a gasp, is known to result in an immediate decrease in ICP and RAP $(2,8)$. Lower ICP and RAP reduces resistance to blood flow and increases cardiac preload and consequently SV and CI. Even small changes in ETP can result in large increases in CI due to the increase in venous return; the effect is amplified in low volume states $(2,9)$. In this study, key physiological parameters, including SBP, MAP, and CI, were all improved with IPR.

In this animal model, piglets developed severe hypotension and severe metabolic acidosis. IPR treatment provided a bridge to more definitive therapy, in this case, blood transfusion. Although there was some metabolic deterioration in the piglets treated with IPR, the severity of the measured metabolic deficit was significantly reduced compared with untreated piglets. These data are similar to those observed in adult pigs subjected to a similar model $(1,3)$. These data are also consistent with initial clinical studies in humans, where $\mathrm{CO}$ and systolic pressures are increased with IPR therapy (4). Lung pathology $24 \mathrm{~h}$ after IPR treatment was assessed in this investigation to demonstrate that the level of negative ITP used in these studies is not detrimental to lung function. There were no significant differences in the wet to dry ratios nor did the piglets show any signs of respiratory distress $24 \mathrm{~h}$ after treatment demonstrating that the technology does not cause pulmonary edema in this model. 
Studies demonstrating the fundamental relationship between a reduction in ITP and the changes in blood flow back to the heart through the abdominal interior vena cava were first reported in 1967 (10). Creating a negative pressure in the chest in a spontaneously breathing individual not only pulls air into the lungs but also pulls blood into the heart. Only recently have technologies been developed that exploit this basic physiological principle. Early studies of this principle in our laboratory were focused on a device called the impedance threshold device (ITD), designed for patients in cardiac arrest or hypotensive spontaneously breathing patients (11-18). The ITD relies on chest wall recoil during cardiac arrest to generate the reduction in ITP. In spontaneously breathing patients, ITP is reduced by breathing through the resistance created by the ITD. IPR therapy, however, uses a generic external vacuum source to lower ITPs and thus enhance venous blood flow back to the heart. This refinement is based on a breakthrough in understanding of the basic physiological principles of blood flow in shock states. By transforming the chest into an active bellows, the combination of a relatively low level of intrathoracic vacuum and intermittent PPV results in a significant augmentation of venous blood flow to the right heart, thereby increasing SV and CO. Contemporaneously, the decrease in ITPs results in a decrease in ICP $(2,6)$. The effect on ICP was a new discovery for us in the process of studying this technology. Lowering ICP results in less resistance to forward cerebral blood flow and thus provides another mechanism, in addition to increased $\mathrm{CO}$, by which cerebral perfusion is enhanced with IPR therapy. Both of these mechanisms may contribute to the increased survival without neurological deficit demonstrated in this study.

This study has limitations. First, the piglets studied had presumably healthy lungs before the study. It is unknown whether IPR will be of benefit in animals or patients with underlying lung pathology. Second, although the animals were randomized, the study was not blinded. Third, our model simulates controlled bleeding and the effects of treatment with IPR during an uncontrolled bleed have not been studied. No intensive care or supplementary fluids was provided to the piglets for $24 \mathrm{~h}$ after reinfusion of blood. Nonetheless, all the survivors functioned normally. Finally, this study did not address the question of potential fluid or drug sparing effects of IPR therapy. These questions will be the subject of future investigations.

There are limitations to the immediate application of this prototype device on patients. Because the current version of the device that provides IPR therapy introduces a vacuum source into a ventilator circuit, ventilator settings may need to be adjusted to prevent spurious triggering of the ventilator and the occurrence of alarms. Furthermore, displayed expiratory tidal and minute volumes may no longer be accurate and would need to be confirmed.

\section{CONCLUSIONS}

In this piglet model of hemorrhagic hypotension and shock, treatment with an IPR device safely and significantly im- proved hemodynamics, prevented acidosis, and improved $24 \mathrm{~h}$ survival. This proof-of-concept study demonstrates that IPR therapy can be safely and efficaciously used in a pediatric piglet model of severe hypotension. IPR is a promising new noninvasive therapy to temporarily improve important hemodynamic parameters when warranted. Based on this study, evaluation of IPR therapy in hypotensive pediatric patients with uncompromised lungs appears warranted.

\section{REFERENCES}

1. Yannopoulos D, Metzger A, McKnite S, Nadkarni V, Aufderheide TP, Idris A, Dries D, Benditt DG, Lurie KG 2006 Intrathoracic pressure regulation improves vital organ perfusion pressures in normovolemic and hypovolemic pigs. Resuscitation 70:445-453

2. Yannopoulos D, McKnite SH, Metzger A, Lurie KG 2006 Intrathoracic pressure regulation for intracranial pressure management in normovolemic and hypovolemic pigs. Crit Care Med 34:S495-S500

3. Yannopoulos D, McKnite S, Metzger A, Lurie KG 2007 Intrathoracic pressure regulation improves 24 -hour survival in a porcine model of hypovolemic shock. Anesth Analg 104:157-162

4. Huffmyer JL, Groves DS, Desouza DG, Littlewood KE, Thiele RH, Nemergut EC 2011 The effect of the intrathoracic pressure regulator on hemodynamics and cardiac output. Shock 35:114-116

5. Yannopoulos D, Nadkarni VM, McKnite SH, Rao A, Kruger K, Metzger A, Benditt DG, Lurie KG 2005 Intrathoracic pressure regulator during continuous-chestcompression advanced cardiac resuscitation improves vital organ perfusion pressures in a porcine model of cardiac arrest. Circulation 112:803-811

6. Yannopoulos D, Aufderheide TP, McKnite S, Kotsifas K, Charris R, Nadkarni V, Lurie KG 2006 Hemodynamic and respiratory effects of negative tracheal pressure during CPR in pigs. Resuscitation 69:487-494

7. Kelley KW, Curtis SE, Marzan GT, Karara HM, Anderson CR 1973 Body surface area of female swine. J Anim Sci 36:927-930

8. Sigurdsson G, Yannopoulos D, McKnite SH, Sondeen JL, Benditt DG, Lurie KG 2006 Effects of an inspiratory impedance threshold device on blood pressure and short term survival in spontaneously breathing hypovolemic pigs. Resuscitation 68:399-404

9. Marino BS, Yannopoulos D, Sigurdsson G, Lai L, Cho C, Redington A, Nicolson S, Nadkarni V, Lurie KG 2004 Spontaneous breathing through an inspiratory impedance threshold device augments cardiac index and stroke volume index in a pediatric porcine model of hemorrhagic hypovolemia. Crit Care Med 32:S398-S405

10. Moreno AH, Burchell AR, Van der Woude R, Burke JH 1967 Respiratory regulation of splanchnic and systemic venous return. Am J Physiol 213:455-465

11. Smith SW, Parquette B, Lindstrom D, Metzger AK, Kopitzke J, Clinton J. An impedance threshold device increases blood pressure in hypotensive patients. J Emerg Med 2010 Jul 13 [Epub ahead of print]

12. Lurie KG, Barnes TA, Zielinski TM, McKnite SH 2003 Evaluation of a prototypic inspiratory impedance threshold valve designed to enhance the efficiency of cardiopulmonary resuscitation. Respir Care 48:52-57

13. Lurie KG, Zielinski T, McKnite S, Aufderheide T, Voelckel W 2002 Use of an inspiratory impedance valve improves neurologically intact survival in a porcine model of ventricular fibrillation. Circulation 105:124-129

14. Lurie KG, Zielinski TM, McKnite SH, Idris AH, Yannopoulos D, Raedler CM, Sigurdsson G, Benditt DG, Voelckel WG 2004 Treatment of hypotension in pigs with an inspiratory impedance threshold device: a feasibility study. Crit Care Med 32:1555-1562

15. Convertino VA, Ryan KL, Rickards CA, Glorsky SL, Idris AH, Yannopoulos D, Metzger A, Lurie KG 2011 Optimizing the respiratory pump: harnessing inspiratory resistance to treat hypotension. Respir Care 56:846-857

16. Convertino VA, Ryan KL, Rickards CA, Cooke WH, Idris AH, Metzger A, Holcomb JB, Adams BD, Lurie KG 2007 Inspiratory resistance maintains arterial pressure during central hypovolemia: Implications for treatment of patients with severe hemorrhage. Crit Care Med 35:1145-1152

17. Convertino VA, Ratliff DA, Ryan KL, Doerr DF, Ludwig DA, Muniz GW, Britton DL, Clah SD, Fernald KB, Ruiz AF, Lurie KG, Idris AH 2004 Hemodynamics associated with breathing through an inspiratory impedance threshold device in human volunteers. Crit Care Med 32:S381-S386

18. Convertino VA, Cooke WH, Lurie KG 2005 Inspiratory resistance as a potential treatment for orthostatic intolerance and hemorrhagic shock. Aviat Space Environ Med 76:319-325 